\title{
Survival of Colletotrichum coccodes in Infected Tomato Tissue and in Soil
}

\author{
H. R. Dillard and A. C. Cobb, Cornell University, New York State Agricultural Experiment Station, Department of \\ Plant Pathology, Geneva 14456
}

\begin{abstract}
Dillard, H. R., and Cobb, A. C. 1998. Survival of Colletotrichum coccodes in infected tomato tissue and in soil. Plant Dis. 82:235-238.

Studies were initiated in 1988 and 1991 to assess long-term survival ability of Colletotrichum coccodes. Sclerotia and infected tomato fruit skin tissue were enclosed in nylon pouches and placed on the soil surface $(0 \mathrm{~cm})$ or buried 10 and $20 \mathrm{~cm}$ deep in fields located in Geneva, New York. Over time, the greatest decline in recovery of $C$. coccodes from tomato skin and decrease in viability of sclerotia were from samples placed on the soil surface. In the 1988 study, after 8 years in the field, 0,90 , and $88 \%$ of the sclerotia were viable, and C. coccodes was isolated from 0,54 , and $86 \%$ of the tomato skin tissues at the $0-, 10-$, and $20-\mathrm{cm}$ soil depths, respectively. In the 1991 study, after 5 years in the field, C. coccodes was isolated from 22, 35, and $37 \%$ of the tomato skin tissues, and 55,91 , and $92 \%$ of the sclerotia were viable at the $0-, 10-$, and 20-cm soil depths, respectively. It is apparent that lengthy crop rotations are required to significantly decrease viable inoculum of $C$. coccodes. In a separate study, $C$. coccodes overwintered in naturally infected tomato roots in commercial fields and was consistently isolated from roots in the fall and the following spring. Fields sampled in the fall yielded similar numbers of plants with infected roots the following spring.
\end{abstract}

Additional keywords: anthracnose, black dot, Lycopersicon esculentum

Tomatoes (Lycopersicon esculentum Mill.) produced in New York are vulnerable to attack by several plant pathogens. One of the most destructive pathogens is Colletotrichum coccodes (Wallr.) S.J. Hughes. The fungus is the causal agent of two distinct diseases of tomato, anthracnose on the fruit $(6,10,11,13,17,20,21)$ and black dot on the roots $(3,6,8,9,13,15$, $18,20,23)$. Initial anthracnose symptoms appear on fruit as light brown flecks; and as the disease progresses, the lesions enlarge and become circular and sunken. Masses of salmon-colored spores are released from the lesions in moist weather, and small black sclerotia are produced in mature lesions. Black dot symptoms initially appear as light brown lesions on the roots, progressing to large brown to gray lesions covered with small black sclerotia-hence the name black dot. The cortical tissue containing the sclerotia may slough off severely infected roots.

Anthracnose is especially difficult to control on tomatoes grown in New York because of regular rainfall, warm temperatures, and high humidity, which are conducive to disease development $(10,11,13,17,21)$. The disease is prevalent on processing tomatoes because of the single, late-season harvest of ripe and

Corresponding author: H. R. Dillard
E-mail: hrd1@ cornell.edu

Accepted for publication 6 November 1997.

Publication no. D-1997-1212-02R

(C) 1998 The American Phytopathological Society overmature fruit. During the growing season, multiple applications of protectant fungicides are made to control the disease $(10,13,17)$. Additional management strategies include planting tomatoes on welldrained land, eliminating weed hosts, using tolerant and resistant cultivars, and using 3- to 4-year crop rotations that exclude crops in the Solanaceae family (2,9,13,17,20-22). In New York, however, unacceptable levels of anthracnose occasionally have developed following the recommended crop rotation period, which has caused some growers to question the usefulness of crop rotation as a strategy for anthracnose control.

Sclerotia of $C$. coccodes develop from acervuli differentiated from a stroma produced on infected plant tissue (25). The sclerotia serve as overwintering and survival structures for the fungus. Results from previous survival studies indicate the sclerotia can survive 2 years in soil $(4,7,12,14,16,18)$.

The objectives of this study were to assess long-term survival of $C$. coccodes in the field as free sclerotia in the soil and in infected tomato tissue for several years, and to assess short-term survival on overwintered, naturally infected tomato roots. Portions of this research were reported previously $(12,14)$.

\section{MATERIALS AND METHODS}

Cultures. Cultures of isolate 210 of $C$. coccodes that originated from tomatoes grown in Lockport, New York, were grown on V8 juice agar $(700 \mathrm{ml}$ of distilled water, $300 \mathrm{ml}$ of V8 juice, $30 \mathrm{~g}$ of Difco Bacto agar, $\mathrm{pH} 4.6$ to 5.0). The cultures were incubated for 41 days at room temperature $\left(20\right.$ to $26^{\circ} \mathrm{C}$ ) in the dark. Sterile distilled water was added to the plates, and the agar surface was scraped gently to dislodge the sclerotia. The suspension was shaken gently for $30 \mathrm{~min}$, the sclerotia were allowed to settle, and the liquid was discarded to remove conidia from the medium. Sterile distilled water was added, the procedure was repeated, and the sclerotia were washed in sterile distilled water a third time. A Millipore filtering system was used to filter the sclerotia into pieces $(3 \times 3 \mathrm{~cm})$ of 155 $\mu$ m-mesh Nitex nylon, which was used because it resists degradation and allows exchange of water, gases, and microorganisms (19). About 100 sclerotia were embedded in each piece of fabric, which was folded in quarters and stapled closed. The fabric containing sclerotia was enclosed in a larger pouch of the same material.

Additional cultures were grown on V8 juice agar for 8 days at room temperature to obtain conidia for inoculating tomato fruit. Sterile distilled water was added to the plates, and the agar surface was scraped gently to dislodge the spores. The suspension was centrifuged, and the supernatant was discarded. Conidia were resuspended in sterile distilled water. Tomato fruit were obtained from greenhousegrown plants. The fruit were rinsed in tap water, surface disinfested in $0.5 \% \mathrm{NaOCl}$ for $3 \mathrm{~min}$, rinsed in sterile distilled water, and allowed to dry in a laminar flow hood. The fruit were puncture inoculated at several different sites with a hypodermic needle containing a spore suspension $(1.1 \times$ $10^{5}$ conidia per $\mathrm{ml}$ ). Inoculated tomatoes were placed on wire racks in closed plastic boxes with hot water added to the bottom to promote high relative humidity. The fruit were incubated 40 days in the boxes at room temperature until large sunken lesions developed and sclerotia were evident. Five large lesions $(1 \times 1 \mathrm{~cm})$ from infected tomato fruit (skin tissue) were enclosed in the large Nytex fabric pouches containing embedded sclerotia.

Survival in soil. On 15 November 1988, 49 pouches were placed on the soil surface $(0 \mathrm{~cm})$ and held in place with rocks, 49 pouches were buried $10 \mathrm{~cm}$ deep, and 49 pouches were buried $20 \mathrm{~cm}$ deep in soil. The pouches were located in a 23-m strip in a 0.4-ha field at the Vegetable Research Farm in Geneva, New York. The soil type was Lima silt loam, pH 6.9 to $7.3,1.9 \%$ organic matter, moderately well-drained, and formed in high lime glacial till. A total of 147 pouches was placed in the field and 
marked with flags to aid in retrieval. At regular intervals, a set of pouches (one each from $0-, 10-$, and 20-cm depths) located adjacent to a flag was retrieved, and sclerotia and tomato skin pieces were assessed for viable $C$. coccodes. Three pouches were not placed in the field, but were used to assess initial viability of the sclerotia and recovery of
C. coccodes from tomato skin pieces.

Isolations were made on V8 juice agar amended with $0.1 \mathrm{~g}$ each of chloramphenicol and streptomycin sulfate per liter. The pouches were unearthed, wiped with a paper towel to remove large soil aggregates, and opened. Fifty sclerotia and all tomato skin pieces and fragments were

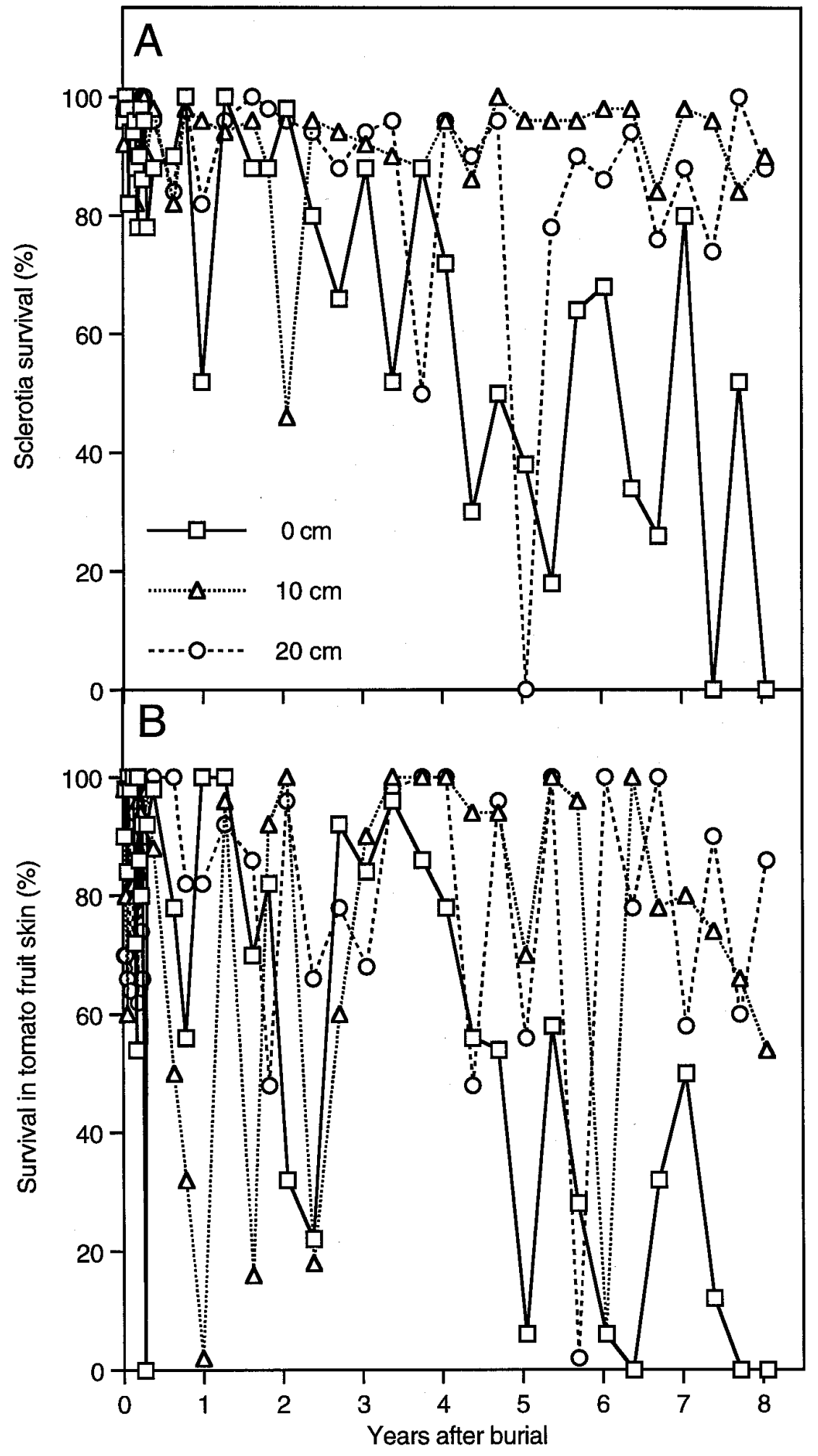

Fig. 1. Survival of Colletotrichum coccodes (A) as sclerotia and (B) in infected tomato fruit skin placed at 0-, 10-, and 20-cm depth in soil on 15 November 1988. Survival was measured as percent viability of 50 sclerotia and percent recovery of $C$. coccodes from 50 tomato fruit skin pieces. removed from the pouches with forceps, surface disinfested in $0.5 \% \mathrm{NaOCl}$ for 4 min, collected on Whatman filter paper no. 1 , and rinsed with sterile distilled water using vacuum filtration. The disinfested sclerotia and tomato skin pieces were placed on the agar medium and incubated for 6 to 8 days at room temperature (21 to $25^{\circ} \mathrm{C}$ ), and the number of $C$. coccodes colonies that developed was recorded. Five sclerotia or five tomato skin pieces were placed on each agar plate (10 plates per burial depth per treatment).

Pouches were retrieved weekly for the first 14 weeks. Because viability was not declining rapidly, pouches were retrieved less frequently to extend the life of the experiment. In 1989 and 1990, pouches were retrieved quarterly. From 1991 to 1996, pouches were collected every 4 months. The last pouches were unearthed on 3 December 1996.

The experiment was repeated in 1991. A total of 156 pouches containing sclerotia or colonized tomato skin pieces was placed in field number 36 at the Vegetable Research Farm in Geneva on 26 November 1991. The soil type was Honeoye fine sandy loam, pH 6.5 to $7.2,2.1 \%$ organic matter, deep and well-drained, and formed in high lime glacial till. The pouches were located in a strip at 52 contiguous sites, and a set of pouches was retrieved every 4 months. Three pouches from each depth $(0,10$, and $20 \mathrm{~cm}$ ) were unearthed at each sampling date. Fifty sclerotia and all tomato skin pieces were removed from each pouch and placed on agar media as previously described. The number of colonies of $C$. coccodes was recorded and, a mean was calculated for each depth. The last pouches were retrieved on 3 December 1996.

Survival on tomato roots. Overwintering of $C$. coccodes on tomato roots was determined in six commercial fields of tomatoes grown for fresh market and processing in 1990 and 1991. Three different fields were selected each autumn. Sampling dates for each field were as follows: location A, 17 October 1990 and 29 April 1991; location B, 29 October 1990 and 8 April 1991; location C, 9 November 1990 and 22 April 1991; location D, 8 October 1991 and 10 April 1992; location E, 15 October 1991 and 15 April 1992; and location F, 21 October 1991 and 20 April 1992. The cropping history of each field sampled in the fall of 1990 and spring of 1991 was as follows: location A, 1990 fresh market tomato (cv. Mountain Pride) from local greenhouse transplants, 1989 fallow, 1988 fallow, 1987 fresh market tomato; location B, 1990 processing tomato (cv. Early Pear, first known tomato crop planted in the history of this field) from southern greenhouse transplants, 1989 sweet corn, 1988 sweet corn, 1987 sweet corn, 1986 alfalfa; location C, 1990 processing tomato (cv. Early Pear, first known tomato crop planted in the history of this field) from 
southern bare-root transplants, 1989 cabbage, 1988 peas, 1987 wheat. The cropping history of each field sampled in the fall of 1991 and spring of 1992 was as follows: location D, 1991 fresh market tomato (cv. Sunrise) from local greenhouse transplants, 1990 sweet corn, 1989 fresh market tomato; location E, 1991 processing tomato (cv. Ohio 8245) from southern greenhouse transplants, 1990 peas, 1989 corn, 1988 corn; location F, 1991 processing tomato (cv. Ohio 8245) from local greenhouse transplants, 1990 sweet corn, 1989 alfalfa.

The tomato fields were divided into 10 sections, and 10 plants were collected randomly from each section, for a total of 100 plants per field. Unearthed tomato root systems were shaken gently to remove large soil aggregates. The plant tops were discarded and the main stems containing the root systems were brought to the laboratory, where the roots were washed in tap water to remove the remaining soil. The roots were examined for the presence of lesions, and 30 root segments 1 to $1.5 \mathrm{~cm}$ in length were cut from each plant. Root segments were selected from brown and necrotic areas on roots, corky roots, and lesions with sclerotia of $C$. coccodes. When symptoms were absent, segments were selected from root tips, stunted rootlets, and areas on the main root. The root segments were surface disinfested in $0.5 \%$ $\mathrm{NaOCl}$ for 4 min and rinsed in sterile distilled water. Six root segments were placed on each of five petri plates containing V8 juice agar amended with $0.1 \mathrm{~g}$ each of chloramphenicol and streptomycin sulfate per liter. The segments were incubated for 2 to 3 weeks at room temperature, and the number of colonies of $C$. coccodes was recorded. No tillage practices were performed in the fall in the sampled areas. The fields were resampled, and population densities of $C$. coccodes were determined using the same technique in the spring of 1991 and 1992, and in the fall of 1991.

\section{RESULTS}

Survival in soil. In the study initiated in 1988, viable sclerotia were recovered through the final sample date in 1996 (Fig. 1A). Prior to placement in the field, $96 \%$

Table 1. Overwinter survival of Colletotrichum coccodes on naturally infected tomato roots in six commercial fields

\begin{tabular}{|c|c|c|}
\hline \multirow[b]{2}{*}{ Field } & \multicolumn{2}{|c|}{ Infected plants (no.) ${ }^{a}$} \\
\hline & Fall & Spring \\
\hline & 1990 & 1991 \\
\hline A & 98 & 96 \\
\hline B & 26 & 39 \\
\hline \multirow[t]{2}{*}{$\mathrm{C}$} & 50 & 33 \\
\hline & 1991 & 1992 \\
\hline D & 95 & 97 \\
\hline E & 88 & 93 \\
\hline F & 8 & 6 \\
\hline
\end{tabular}

of the sclerotia were viable. After 4 years in the field, viability of sclerotia was $50 \%$ or higher at all depths. On the final sampling date, after 8 years in the field, 0,90 , and $88 \%$ of the sclerotia were viable at the $0-, 10-$, and $20-\mathrm{cm}$ soil depths, respectively. C. coccodes was isolated from $98 \%$ of the tomato skin pieces prior to placement in the field. There was substantial variability in recovery of $C$. coccodes from tomato skin during the 8 years of study (Fig. 1B). Common soil inhabitants (Trichoderma, Rhizopus, and Mucor spp.) were isolated frequently from tomato skin. On the final sample date, $C$. coccodes was isolated from 0,54 , and $96 \%$ of the tomato skin pieces at the $0-, 10-$, and $20-\mathrm{cm}$ soil depths, respectively. Recovery of $C$. coccodes from tomato skin and viability of sclerotia decreased most in samples placed on the soil surface (Fig. 1A and B).

Results of the 1991 study were similar, but recovery of $C$. coccodes from tomato skin tissue was less. Prior to placement in the field, $C$. coccodes was isolated from only $46 \%$ of the tomato skin pieces, and $98 \%$ of the sclerotia were viable. Longterm survival was greatest and most consistent among the buried sclerotia (Fig. 2A). Survival in infected tomato skins was

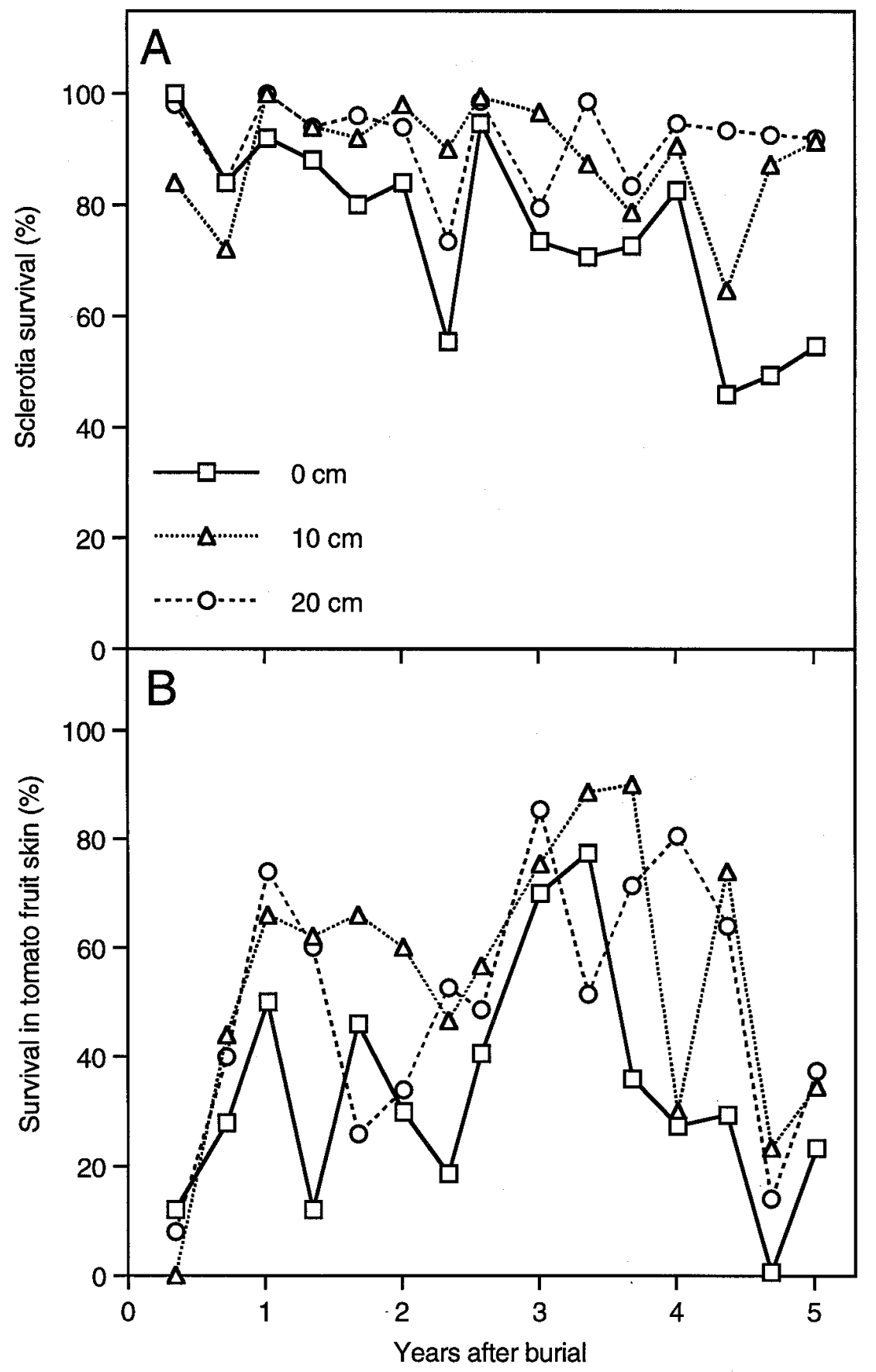

Fig. 2. Survival of Colletotrichum coccodes (A) as sclerotia and (B) in infected tomato fruit skin placed at 0-, 10-, and 20-cm depth in soil on 26 November 1991. Survival was measured as percent viability of 50 sclerotia and percent recovery of $C$. coccodes from 50 tomato fruit skin pieces. 
lower and fluctuated throughout the study period (Fig. 2B). Species of Trichoderma, Rhizopus, and Fusarium were isolated frequently from tomato skin tissue. On the final sampling date, after 5 years in soil, $C$. coccodes was isolated from 23, 35, and $37 \%$ of the tomato skin pieces, and 55, 91, and 92\% of the sclerotia were viable at the $0-, 10-$, and 20-cm depths, respectively (Fig. 2A and B).

Survival on tomato roots. $C$. coccodes was isolated in the fall from tomato roots in fields with and without a previous cropping history of Solanaceous crops. The fungus successfully overwintered on naturally infected tomato roots and was isolated consistently from roots the following spring (Table 1). Although the tomato roots had decayed significantly over the winter months, there were no significant decreases in viable inoculum of $C$. coccodes.

\section{DISCUSSION}

The results of this study clearly demonstrate the ability of $C$. coccodes to survive in field soils for at least 8 years. The fungus produces sclerotia on infected plant tissues, and these structures provide long-term survival ability. Previous studies have shown that $C$. coccodes is able to survive at least 2 years in soil $(4,7,12,14,16,18)$. This is the first study to follow survival of $C$. coccodes for 5 (1991 burial) and 8 (1988 burial) years in the field. Other sclerotia-forming fungi with recorded survival of $\geq 8$ years include Phymatotrichum omnivorum, Sclerotinia trifoliorum, and Verticillium dahliae $(1,7)$.

Sclerotia survival is influenced by location in soil and association with plant tissue $(1,5,7,12,14,16,19,24)$. In our study, sclerotia survived longer and more consistently when they were free in the soil versus associated with plant tissue. Isolations from infected tomato skin tissue frequently yielded fast-growing soil inhabitants (Trichoderma, Rhizopus, Fusarium, and Mucor spp.) that colonized the tissues and interfered with the isolation procedure or parasitized the sclerotia that were produced in the skin lesions. Survival of $C$. coccodes was less on the soil surface than at 10 or 20 $\mathrm{cm}$ deep, which likely was due to greater fluctuation in temperature and moisture at the soil surface. Our results contrast with those reported for $C$. graminicola, whose survival percentage after 18 months was highest in sorghum stalks located on the soil surface and was reduced significantly when buried (5). Sclerotia survival for 8 years in nature has been reported for Sclerotinia trifoliorum when the sclerotia were buried deeper than $6.4 \mathrm{~cm}$ (1).

The sclerotia of $C$. coccodes structurally resemble those formed by Typhula species (25). The sclerotia have three layers: a central medulla with free or partly agglutinated hyphae, a cortex with agglutinated hyphae, and an epidermis with superficial hyphae (25). Coley-Smith and Cooke (7) list the survival period for $C$. coccodes as 83 weeks, with $53 \%$ of the sclerotia sur- viving after placement in moist garden soil in a glasshouse. The survival time for $T y$ phula incarnata was 25 months in dry soil. Thus, one would expect survival of $C$. coccodes sclerotia to be at least 2 years. Data from our 8-year study indicate over $50 \%$ of the sclerotia at any depth survived the first 4 years. Generally, survival remained over $50 \%$ for the final 4 years of study at the 10- and 20-cm depths, but was reduced at the soil surface.

Tomato roots are a hidden source of conidia and sclerotia of $C$. coccodes. In four of the six commercial fields we sampled, the tomato plants appeared healthy aboveground and there were few fruits with anthracnose, but $C$. coccodes colonized and produced sclerotia on the roots. Sclerotia production on tomato roots is an efficient method for the fungus to maintain high populations in the soil. It is interesting to note that $C$. coccodes was isolated from tomato roots in two fields (locations B and C) that had no previous tomato or other solanaceous cropping history. Although the fungus is primarily pathogenic on plants in the Solanaceae and Cucurbitaceae, it has a wide host range encompassing several plant families and has been isolated from symptomless roots of chrysanthemum, white mustard, cress, cabbage, and lettuce $(6,20)$. Location $C$ had a crop of cabbage prior to tomatoes, and cabbage is a known symptomless host (6).

Fresh market and processing tomato producers in New York have stated consistently that recommended crop rotations of 3 to 4 years have not alleviated disease pressure from $C$. coccodes. Our results support their observations, as it is apparent that once $C$. coccodes is established in a field, the recommended 3- to 4-year crop rotation is not sufficient to result in a significant decrease in viable inoculum. Similar results were found with Sclerotinia sclerotiorum, where a 3-year crop rotation did not reduce sclerotium populations significantly (24). However, we support the practice of multiple-year rotations with nonhost crops before anthracnose and black dot become problems in order to prevent an increase of $C$. coccodes sclerotia in soil.

\section{ACKNOWLEDGMENTS}

We gratefully acknowledge advice from W. Garman and E. Rutkowski; the enthusiastic participation of J. Peterson, D. Stuart, and K. Welch; and the temporary assistance of D. Brink, D. Cobb, D. Hoffman, J. Ingram, K. Jensen, and K. McCormick. This research was supported in part by the New York State Tomato Research Association and Cornell Cooperative Extension.

\section{LITERATURE CITED}

1. Adams, P. B., and Ayers, W. A. 1979. Ecology of Sclerotinia species. Phytopathology 69:896-899.

2. Andersen, R. N., and Walker, H. L. 1985. Colletotrichum coccodes: A pathogen of eastern black nightshade (Solanum ptycanthum). Weed Sci. 33:902-905.

3. Barkdoll, A. W., and Davis, J. R. 1992. Distribution of Colletotrichum coccodes in Idaho and variation in pathogenicity on potato.
Plant Dis. 76:131-135.

4. Blakeman, J. P., and Hornby, D. 1966. The persistence of Colletotrichum coccodes and Mycosphaerella ligulicola in soil, with special reference to sclerotia and conidia. Trans. Br. Mycol. Soc. 49:227-240.

5. Casela, C. R., and Frederiksen, R. A. 1993. Survival of Colletotrichum graminicola sclerotia in sorghum stalk residues. Plant Dis. 77:825-827.

6. Chesters, C. G. C., and Hornby, D. 1965 Studies on Colletotrichum coccodes. II. Alternative host tests and tomato fruit inoculations using a typical tomato root isolate Trans. Br. Mycol. Soc. 48:583-594.

7. Coley-Smith, J. R., and Cooke, R. C. 1971 Survival and germination of fungal sclerotia. Annu. Rev. Phytopathol. 9:65-92.

8. Colquhoun, T. T. 1941. Black dot root rot of tomatoes. J. Agric. South Aust. 44:572-575.

9. Dashwood, E. P., Fox, R. A., and Perry, D. A 1992. Effect of inoculum source on root and tuber infection by potato blemish disease fungi. Plant Pathol. 41:215-223.

10. Dillard, H. R. 1987. Tomato anthracnose. Page 735.70 in: Vegetable Crops Fact Sheet. Cornell Cooperative Extension.

11. Dillard, H. R. 1989. Effect of temperature, wetness duration, and inoculum density on infection and lesion development of Colletotrichum coccodes on tomato fruit. Phytopathology 79:1063-1066.

12. Dillard, H. R. 1990. Survival of Colletotrichum coccodes in New York. (Abstr.) Phytopathology 80:1026.

13. Dillard, H. R. 1992. Colletotrichum coccodes: The pathogen and its hosts. Pages 225-236 in: Colletotrichum: Biology, Pathology and Control. J. A. Bailey and M. J. Jeger, eds. CAB International, Wallingford, UK.

14. Dillard, H. R., and Cobb, A. C. 1993. Persistence of Colletotrichum coccodes on tomato roots and in soil. (Abstr.) Phytopathology 83:1345.

15. Dunn, E., and Roy, A. K. 1970. Infection of tomato seedlings by Colletotrichum coccodes (Wallr) Hughes. Plant Pathol. 19:196-197.

16. Farley, J. D. 1976. Survival of Colletotrichum coccodes in soil. Phytopathology 66:640-641.

17. Fulling, B. A., Tigchelaar, E. C., and Latin, R. 1995. Integration of host resistance and weather-based fungicide scheduling for control of anthracnose of tomato fruit. Plant Dis. 79:228-233.

18. Hornby, D. 1968. Studies on Colletotrichum coccodes III. Some properties of the fungus in soil and in tomato roots. Trans. Br. Mycol. Soc. 51:541-553.

19. Lumsden, R. D. 1981. A nylon fabric technique for studying the ecology of Pythium aphanidermatum and other fungi in soil. Phytopathology 71:282-285.

20. Mordue, J. E. M. 1967. Colletotrichum coccodes. Descriptions of Pathogenic Fungi and Bacteria. No. 131. Commonw. Mycol. Inst./ Assoc. Appl. Biol., Kew, Surrey, England.

21. Precheur, R. J., Bennett, M. A., Riedel, R. M., and Dudash, P. J. 1990. Effect of tomato variety on efficacy of chemical control of anthracnose, 1988. Biol. Cult. Tests Control Plant Dis. 5:35.

22. Raid, R. N., and Pennypacker, S. P. 1987. Weeds as hosts for Colletotrichum coccodes. Plant Dis. 71:643-646.

23. Schneider, R. W., Grogan, R. G., and Kimble, K. A. 1978. Colletotrichum root rot of greenhouse tomatoes in California. Plant Dis. Rep. 62:969-971.

24. Schwartz, H. F., and Steadman, J. R. 1978. Factors affecting sclerotium populations of, and apothecium production by, Sclerotinia sclerotiorum. Phytopathology 68:383-388.

25. Tu, J. C. 1980 . The ontogeny of the sclerotia of Colletotrichum coccodes. Can. J. Bot. 58:631-636. 